\title{
Controlling in der Krise
}

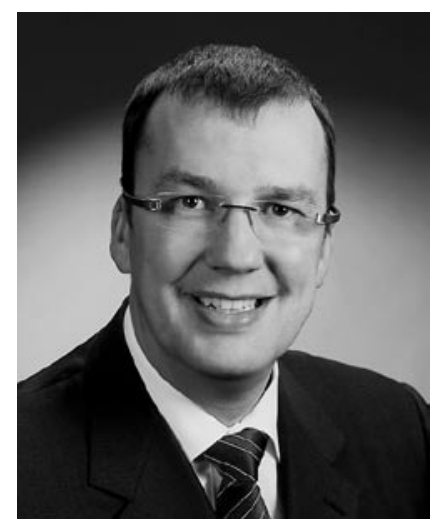

\section{Utz Schäffer}

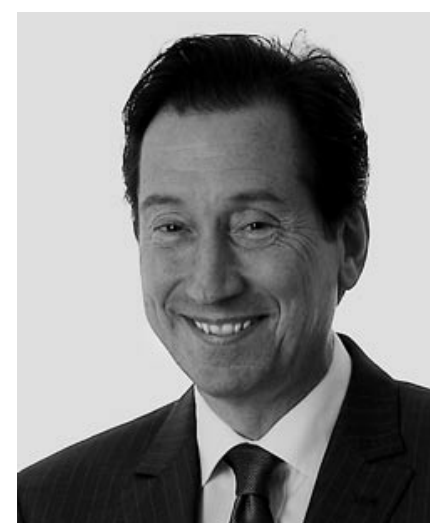

\section{Jürgen Weber}

\section{Liebe Leser,}

"Controlling in der Krise" ist ein doppeldeutiger Titel. Zum Glück für die Controller markiert er nicht etwaige Existenzängste für die eigene Profession. Controller sind seit geraumer Zeit in den Unternehmen fest im Sattel. Ihre Bedeutung ist in den letzten Jahren ebenso angestiegen wie der Umfang ihrer Aufgaben. Wenn auch der Controller als Berater und Counterpart schon lange postuliert wurde - übrigens von „gestandenen Praktikern“ ebenso wie von Seiten der Wissenschaft -, hat man erst seit wenigen Jahren die empirische Gewissheit, dass der Controller in immer mehr Unternehmen auf der Stufe des unverzichtbaren Partners des Managers angekommen ist.

Controlling in der Krise meint vielmehr die immensen Herausforderungen, mit denen die Controller in Zeiten der Wirtschaftskrise konfrontiert werden. Zwar sind noch nicht alle Unternehmen von dieser Krise betroffen - von Monat zu Monat steigt diese Zahl aber ebenso an wie der Grad der Betroffenheit: Längst glaubt die Mehrheit nicht mehr an einen V-förmigen Verlauf der Krise, und zur Prognose eines U-förmigen Verlaufs gesellen sich vereinzelt auch schon Stimmen, die von einem $L$ ausgehen.

Für Controller bedeutet die Krise unmittelbar zunächst einmal mehr Arbeit - verbunden mit einer entsprechend längeren Arbeitszeit. Controller sind laufend gefordert, aktuelle Prognosen abzugeben. Sie werden von ihren Managern verstärkt für Sonderanalysen und Projekte herangezogen. Ihr Rat ist gefragt; gleichzeitig steigt ihr Einfluss beim Management. Controller sind gänzlich unverzichtbar geworden. Es gilt die alte Weisheit: Schlechte Zeiten des Unternehmens sind gute Zeiten für Controller.

Für Übermut ist allerdings keinerlei Anlass. Die Wirtschaftskrise greift nämlich das Selbstverständnis der Controller an zwei zentralen Punkten vehement an:

Auf der einen Seite zeigt die Krise geradezu brutal Grenzen der Planung auf. Das von Controllern gestaltete ausgefeilte, vernetzte und komplexe System der operativen Planung ist durch die Strukturbrüche mit Umsatzrückgängen von stellenweise über 50 \% und den Eskapaden der Rohstoffpreise arg in Frage gestellt worden. Viele Unternehmen müssen derzeit einfach „auf Sicht " fahren. Wie die operative Planung für das kommende Jahr aussieht und wie daran welche Incentivierungen geknüpft sind, steht in den Sternen. Entsprechende Ausstrahlungswirkungen auf die Mittelfristplanung und die strategische Planung sind zu erwarten. Die Sicherheit, die Controller mit ihrer Planungsmaschinerie suggeriert haben, ist in Folge der Krise einer gewissen Fassungslosigkeit gewichen.

Auf der anderen Seite werden Controller aktuell wieder auf eine Tätigkeit konzentriert (um nicht zu sagen: reduziert), die sie längst überwunden glaubten. Sie werden wieder zum Sparkommisar des Unternehmens. Cost-cutting-Programme beherrschen das Feld; kaum ein Unternehmen kommt daran vorbei, und zumeist sind es die Controller, die hier den Lead haben. Zum Glück haben sie dieses Geschäft in den vergangenen Boom-Zeiten nicht verlernt; zum Glück ist die Bereitschaft des Managements zu sparen angesichts der immensen, nie gekannten Umsatzrückgänge so hoch wie noch nie. Dennoch besteht die Gefahr, dass mit dem intensiven Sparen auch das Bild des Bremsers und Verhinderers zurückkommt und das Rollenbild prägt. In wieder besseren Zeiten zum „,business partner“ zurück zu wechseln, ist kein Selbstläufer!

Die schlechten Zeiten sollten deshalb nicht zu lange dauern. Das ist weder den Unternehmen noch ihren Controllern zu wünschen!
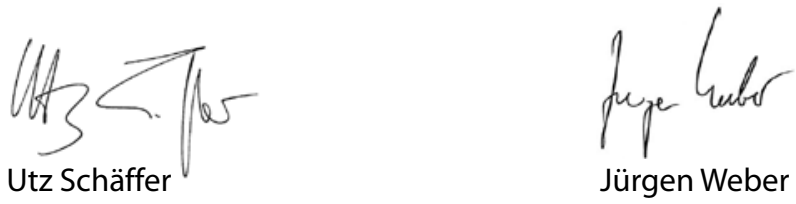